\title{
Network approaches for understanding rainwater management from a social- ecological systems perspective
}

\author{
Steven D. Prager ${ }^{1}$ and Catherine Pfeifer ${ }^{2}$
}

\begin{abstract}
The premise of this research is to better understand how approaches to implementing rainwater management practices can be informed by understanding how the people living and working in agroecosystems are connected to one another. Because these connections are via both social interactions and functional characteristics of the landscape, a social-ecological network emerges. Using social-ecological network theory, we ask how understanding the structure of interactions can lead to improved rainwater management interventions. Using a case study situated within a small sub-basin in the Fogera area of the Blue Nile Basin of Ethiopia, we build networks of smallholders based both on the biophysical and social-institutional landscapes present in the study site, with the smallholders themselves as the common element between the networks. In turn we explore how structures present in the networks may serve to guide decision making regarding both where and with whom rainwater management interventions could be developed. This research thus illustrates an approach for constructing a social-ecological network and demonstrates how the structures of the network yield insights for tailoring the implementation of rainwater management practices to the social and ecological setting.
\end{abstract}

Key Words: network theory; social-ecological network; social-ecological systems; spatial data; spatial resilience; watershed management

\section{INTRODUCTION}

Our aim in this paper is to assess the usefulness of socialecological network approaches (Janssen et al. 2006) as a means for understanding and improving the manner in which rainwater management interventions are designed and implemented in agroecosystems. In agroecosystems, water is not simply a resource supporting food production, it also serves a fundamental role in connecting both places and people (Ripl 2003). Water management must thus be examined from solely a physical perspective (Nyssen et al. 2004), but also from a combined social and ecological perspective (Rathwell and Peterson 2012). We are accustomed to this perspective in surface water management, for example in considering irrigation, but it is equally true in rain-fed agroecosystems where multiple actors manage rainwater for different purposes over different scales in space and time. Recognizing that social and ecological systems cannot be treated independently in management and policy contexts (Folke et al. 2002), efforts to understand and engage stakeholders in such systems must take both the physical and human environments into consideration.

The context of this work is in Ethiopia, where rain-fed agriculture predominates and rainwater management poses a particular social-ecological coordination challenge. Rainwater is managed by smallholders at the plot or farm scale through rainwater management practices (RMPs). RMPs are combinations of agricultural practices that aim to increase water productivity or availability and can include soil and water conservation, reafforestation, or river diversion. The intention of these practices is to improve water availability or quality at watershed levels. In some instances, however, the positive impacts of RMPs may not directly benefit the smallholder who has implemented the practice. Whether or not any specific individual benefits from RMPs is dependent on both their own social-ecological context and the similar context of others in the watershed. First, the impact might be significant only if neighboring smallholders also implement the practice, which is the case for most soil and water conservation practices such as terraces and soil bunds that slow the movement of water and thus reduce erosion when sufficient area is adequately treated. Second, beneficial impacts might accrue to others downstream, such as reduced sedimentation through afforestation efforts. The lack of direct benefits, the difficulties in coordinating activities among neighbors, and the challenges associated with implementing benefit sharing mechanisms linking upstream and downstream smallholders explain, to a large extent, the low up-take of RMPs in Ethiopia and elsewhere.

To design interventions in such systems, it is important to understand not only how people are connected through water and land but also socially. The uneven distribution of benefits from RMPs and even the potential for disincentives in some cases, e.g., reduction in productive area, requires understanding of both ecological and social dynamics within the system. As such, knowing where to begin an intervention process is often one of the most challenging tasks, with approaches needed to facilitate understanding of both the physical and social structures present in the system and how those structures might be related to system resilience. Resilience of such systems to perturbations, such as that associated with climate variation, and the ability of the system to reorganize and recover (Abel et al. 2006) is heavily dependent on spatial variation, flows, and connectivity within the system. Cumming (2011:54) points out that network analytic approaches are useful for understanding structures associated with spatial resilience and that such approaches, "can identify nodes that are particularly important for overall network connectivity; they may not be the largest or most resource-rich nodes, and hence might be easy to overlook without a more formal analysis." Both the ecological and social aspects of the networks are important because measures of connectedness can serve as an indicator both of ecological function (Urban and Keitt 2001) and as the potential of a community ability to manage common property resources (Abel et al. 2006). 
Considering the above, network approaches offer promise in rainwater management scenarios, specifically for identifying nodes that may serve as indicators or entry points for improved understanding and management of common property resources. Specifically, in a social-ecological systems context, humanenvironment systems have been described in terms of socialecological networks (Janssen et al. 2006). In a synthesis reviewing several examples of social-ecological systems, Janssen et al. (2006) offer a formalization of social-ecological networks and describe three archetypes for such networks:

1. Ecosystem networks connected by people via information or material flow,

2. Ecosystem networks disconnected or fragmented by anthropogenic change,

\section{Ecosystem networks that connect people.}

As formalized above, social-ecological networks simultaneously capture the relationship of people to their environment and the role of the environment in relating people to one another. The value of the network representation arises from the intrinsic ability of the network to capture structures present within the system representation (Bodin et al. 2006). Variations of these approaches have been applied in applications more strictly oriented around landscape and connectivity (Estrada and Bodin 2008), as well as applications more specifically emphasizing the roles and relationships of individuals and institutions (Bodin and Crona 2009, Prell et al. 2009). Recognizing that social networks are nearly invisible in many landscape analyses, Beilin et al. (2013) demonstrated the qualitative efficacy in using social network analysis for making the social aspects of landscape. Arguably a subset of a more general social-ecological systems frameworks (Binder et al.2013), social-ecological networks offer one approach for understanding both where and how the structure of system may potentiate or inhibit positive change.

In the rainwater management context, successful implementation of RMPs requires consideration and coordination across a complex set of up-stream/down-stream benefit transfers and dispersed activities to realize return on investment. Given that structures within the social-ecological network may potentiate or inhibit change (Bodin et al. 2006), it follows that social-ecological networks at the local level might be useful in identifying entry points into the system that may have the potential to reinforce centrifugal forces, aspects that help keep a system together, and minimize centripetal forces tending to pull the system apart (Cumming 2011), thus having a positive impact on coordinating individual decision makers to adopt specific practices to increase overall watershed resilience. In the case of water management, there is a strong scale component because effective water management at larger spatial scales requires collective management action at the microscale levels (Ryan et al. 2010).

As with any type of network analysis, the combination of the underlying representation and choice of analytic approach ultimately drives results, and interpretation must be framed accordingly. Analyzing the structures present in social-ecological networks (SENs) uses many of the same approaches common to social network analysis more generally. In contrast to social networks, however, SENs are inherently mixed modality. In SENs, nodes may be individuals with connecting edges determined by the environment or, alternatively, nodes may represent locations in space and the people moving between those spaces may be the connecting edges. The meaning of the structures present in SENs is thus different as well, for in social networks individuals are the primary determinant of the network topology and, ultimately, the basis for resilience of the network to perturbation (Ehrhardt et al. 2007). In contrast, SENs are necessarily spatially embedded and thus subject to the additional effects of space on their structural characteristics and corresponding response to perturbation (Wong et al. 2006). With all three of the Janssen et al. (2006) archetypes explicitly building on ecosystem and social characteristics, a simultaneous view of both the social and the ecological aspects of connectivity is required.

The wide range of potential representations for social-ecological networks coupled with the fact that even an individual network may be represented in multiple ways makes it difficult to determine optimal approaches when conducting a new study. In an assessment of several case studies involving participatory processes and stakeholder interactions, Reed et al. (2009) showed that different objectives necessarily require different types of engagement and data. More specifically in relation to SENs, typical examples tend to be based on relatively large scale ecosystems and institutional interactions (Janssen et al. 2006, Rathwell and Peterson 2012, Beilin et al. 2013). Understanding small-scale variation is also important, for although small-scale systems may be able to suppress some consequences of local variation by integrating over space and time, the necessary social and ecological infrastructure to accomplish this integration may actually increase vulnerabilities to processes operating at other scales (Levin and Clark 2010). With this in mind, this study is explicitly designed from the ground up around the idea of SENs, and aims to test their utility at a local and individually oriented level in an attempt to address the following questions:

- Are SENs a practical tool for bottom-up understanding the spatial resilience of social-ecological systems at the individual level and highly local scale?

- Can understanding of such SENs contribute to a better understanding on how to focus interventions in a watershed to promote improved rainwater management?

The challenges with understanding social-ecological networks at a local level arise from the sample frames and granularity required to achieve a sufficient representation of the nature and interconnections present in the system in question. Within this framework, we evaluate a specific agroecosystem in a small watershed in Ethiopia to assess the bottom-up potential of SENs in programing rainwater management interventions. We offer one approach for developing and characterizing social-ecological networks as a basis for using spatial resilience concepts to promote improved rainwater management.

\section{STUDY SITE AND METHODS}

The emphasis of this study is on evaluating whether socialecological networks can be used to identify entry points into agroecosystems that have the potential to enable or enhance the effectiveness of interventions associated with the implementation of rainwater management practices. In determining whether there either exists or is the potential for centrifugal and centripetal forces, this work offers perspective into the function of both the 
ecological and social aspects of the study site. For this reason, data collection and analytic methods are structured around understanding a number of social variables, a number of environmental variables, and the manner in which they are nested with one another.

\section{Study site characteristics}

A legacy of land-use practices is widely acknowledged to have had a significant influence on current environmental conditions (Elmore et al. 2006). In Ethiopia, it is often argued that the nationalized land tenure models that arose during the imperial regime of Haile Selassie and the socialist Derg regime that followed have had serious negative consequences on environmental conditions and, ultimately, failed because of lack of consideration of local social and environmental contexts (Molle 2007). The failures in land management have contributed to a great deal of land degradation, soil loss, and water management issues (Merrey and Gebreselassi 2011). The issue of water management is particularly pressing because the majority of Ethiopian agriculture is rain-fed, excessive runoff leads to soil loss, and, furthermore, a substantial portion of the country (approximately 200,000 $\mathrm{km}^{2}$ ) belongs to the Blue Nile basin (Merrey and Gebreselassi 2011), which is of great international import. The International Water Management Institute (IWMI), a key contributor to research and capacity building in the Blue Nile basin, has established several research sites in sub-basins within the region.

The site for this study is a small sub-basin of one of the watersheds in which IWMI has a research presence. The basin is located in the Fogera woreda (a woreda is a third-level administrative district political boundary). Estimated population of the entire IWMI research watershed is 1239 people, with an estimate of 379 people in the sub-basin specific to this study (Linard et al. 2012). Approximately $600 \mathrm{~km}$ from the Ethiopian capital city of Addis Ababa and just south of the well-known intentional community of Awra Amba, the study site is accessible only through a combination of vehicular and foot travel. There are no roads in the study area, and travel on foot is via an extensive network of paths that link smallholder dwellings and farming plots. Many of the paths ultimately lead to the adjacent and downstream Awra Amba community and, in turn, to a paved road running east-west between the towns of Wereta and Debre Tabor. In several places, these paths are bisected and heavily eroded by the two main streams in the study area. The paths are not suitable for wheeled devices and human and animal labor is used to transport goods into and out of the area. Smallholders do not use mechanized equipment, but many use oxen for plowing. Labor, including plowing, planting, fertilizing, and harvesting is performed by hand. Areas that are not actively farmed or grazed tend to be covered in herbaceous or woody vegetation.

There are several crop types common to the area, including teff (Eragrostis tef), millet (Eleusine coracana), peanut (Arachis hypogaea), maize (Zea mays), potato (Solanum tuberosu), and eucalyptus (Eucalyptus spp.). The soils are generally sandy clay with limited organic matter present. Much of the area has terracing of various sorts and many of the terraces were reported to have been in place since the Derg regime. Five common grazing areas were identified, each used by both local and itinerant grazers.

\section{Data collection}

Given the integrated nature of a social-ecological network, both social and ecological data are required to adequately characterize the study site. Two sets of field data were collected simultaneously, including survey data to understand the social situation and spatial data to characterize the landscape and ecological situation. The data collection process was conducted over the course of several visits to the study side during a six-week period in July and August of 2011. Access to the study site required initial conversations with the Head of the Fogera woreda Office of Agriculture and Rural Development and local kebele (the smallest administrative area) officials.

The survey data collection process and resultant analytic approach needed to account for the time of year. The data collection occurred during kremt (the rainy season) and, consequently, data collection needed to be designed around the availability of smallholder farmers. During kremt, many of the smallholders and community members are in the field either preparing fields, planting, or weeding depending on their position in the watershed and specific crops. The survey developed for this effort was designed for short interactions to minimize community interference and time away from important agricultural priorities. The survey captured data in two key categories. The first set of questions (see Appendix 1) were related to social capital with a number of questions derived from vetted World Bank work in social capital assessment (Grootaert and Bastelaer 2002). The second set of questions was designed to provide a preliminary evaluation regarding the types of social interactions prevalent in the watershed (see Appendix 2). Combined teams of students from Ethiopia and the United States conducted surveys during each of the field campaigns.

To support alignment of the social and ecological components of the system, plot data associated with individual fields were collected during each of the individual interviews (Fig. 1). Where possible, the boundary of each surveyed plot was walked and mapped via GPS. In a small number of cases, a point just inside a plot was recorded and the plot was later mapped using Google Earth. In total, 215 plots were mapped using GPS in the field or via recent imagery.

Although not the focus of the present study, the mapping effort also included a "rapid ecological assessment" (REA) and was

Fig. 1. Maps of the study site.

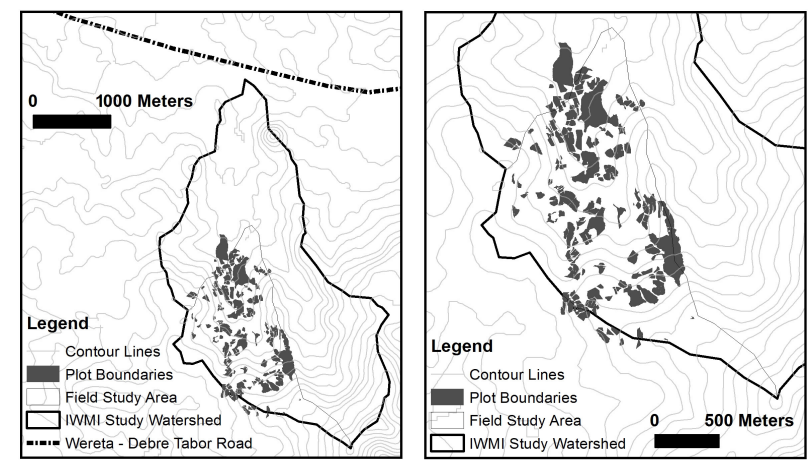


divided into two parts: an assessment of vegetation status and an assessment of each plot's physical characteristics. For the vegetation status, a simple presence/absence description was used. The recorded variables included trees, vegetation strips (typically noncrop vegetation growing in a linear fashion along plot boundaries), plant litter, and grass. An estimate of noncrop to crop ratio was recorded, as was the type of crop. For the physical variables, the presence and absence of bunds, terraces, contour ploughing, standing water, and drainage ditches was recorded. In addition, simple soil characteristics were recorded (clay, sand, or loam) as well as an estimate of density of surface rocks per square meter. Each of the variables in the REA was quantified by sight and information regarding crop types and agriculture management practices came from the farmers themselves.

\section{Social-ecological network creation}

As previously mentioned, this study was designed to evaluate whether SENs have bottom-up utility for understanding highly local aspects of social-ecological systems. Given the position of the study site in the Blue Nile basin and the role of rainwater management in supporting spatial resilience both locally and basin-wide, our focus is on understanding SENs in a water management context. Janssen et al. (2006) suggest there is no "right" way to represent the SEN of a given system, just "useful and not so useful" ways. The impetus of the approach presented here hinges on the idea that there is a gap between policy recommendations at a regional level, e.g., Blue Nile basin, and its implementation at a local level. The central premise then, is that it may be possible to conceptualize policy goals in terms that foster spatially appropriate types of self-organization, increasing resilience, and reducing vulnerability to regional scale variation in market and environmental conditions (Cumming and Collier 2005).

Integral to this effort is the motive to increase understanding of what types of social-ecological networks are relevant in what contexts. As mentioned, the three SEN archetypes include, (1) ecosystem networks connected by people via information or material flow, (2) ecosystem networks disconnected or fragmented by anthropogenic change, and (3) ecosystem networks that connect people (Janssen et al. 2006). The methods presented here are aimed at developing Archetype 3 networks, or ecosystem networks that connect people, with specific relevance to the aforementioned rainwater management context.

Underlying the developed approach is that the hydrological system essentially connects individuals (Ripl 2003), willingly or not, and knowingly or not. Depending on position in the landscape, individuals are necessarily connected to others and the actions of upstream individuals may affect those downstream. These effects may either be immediate, or may accumulate over time. This is, of course, nothing new from a conceptual perspective, but this idea offers a potentially useful framework for understanding biophysical connectivity between individuals at a landscape scale.

To connect individuals in their biophysical context, the first step is to create a weighted network of plots based on a hydrological flow accumulation model. Flow accumulation is an analysis based on a digital elevation model (DEM) that maps theoretical downhill flow and concentration of water within a basin (Quinn et al. 1991). Using the centroid of each of the digitized plots as a starting point, it is then possible to compute the flow path through the watershed DEM of all water originating at that point and ending at an arbitrary "pour point" (equivalent to the sub-basin outlet) just below the study area. This path represents the notional path that water, sediment, and potential contaminants would flow downhill and downstream from any given plot. Note that, given the resolution of the underlying DEM, this process does not account for barriers such and bunds, terraces, ditches and other diversions. Nevertheless, at the scale of the present study, the approach does characterize the potential for upstreamdownstream biophysical interactions tied to the movement of water and does lay the groundwork for higher resolution analyses. Figure 2 illustrates the method using a set of eight hypothetical plots and their alphanumeric IDs (where the number represents the individual owner and the letter enumerates multiple plots), demonstrating how downstream flows directionally connect plots higher in the watershed to plots lower in the watershed.

Fig. 2. The model used to connect plots and, by extension, individuals to one another.

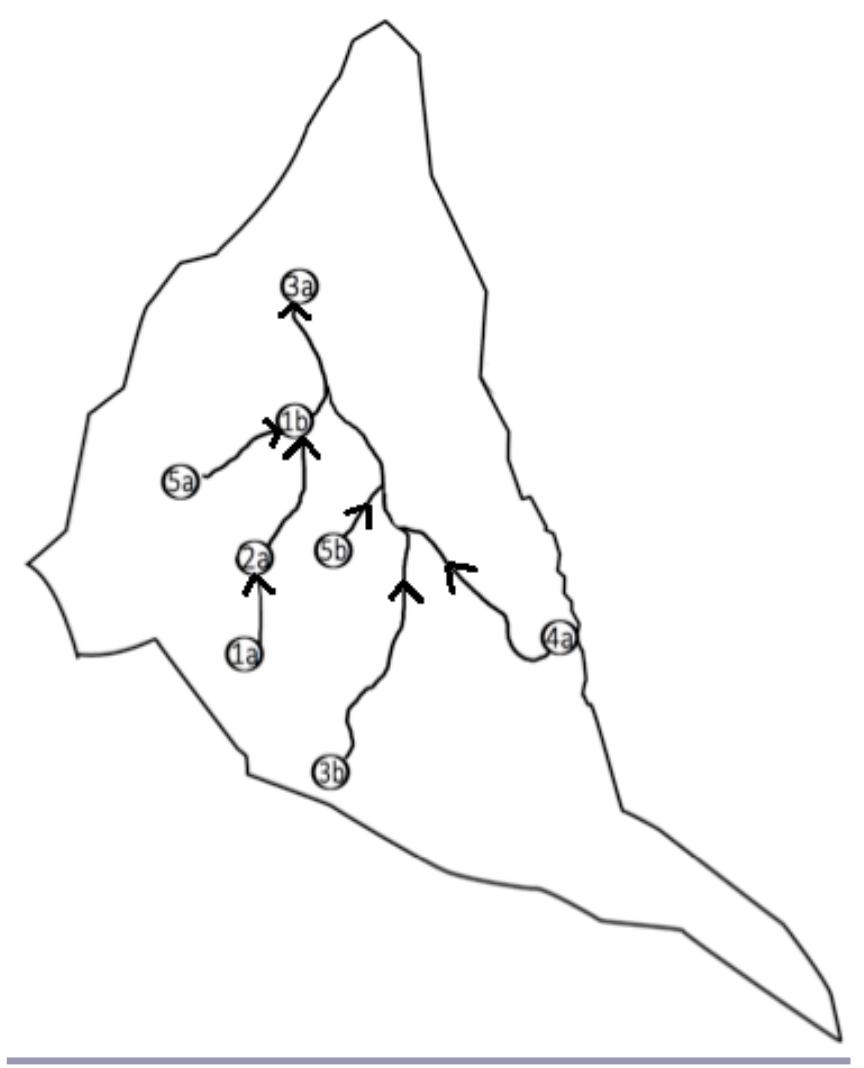

The computed flow path intersects all plots downstream relative to the location to the focal plot. Using this flow path, each of the other digitized plots in the study area is queried using a spatial intersection operation. This query determines which plots are connected to the focal plot by way of the runoff path and the process is repeated for every plot. The topography of the landscape in combination with the location of each plot thus results in a directed network topology indicating plot-plot interactions. The result is a network of individual plot relationships to one another (Fig. 3a). From this network, plot- 
to-plot connectivity over the study area as a whole can be easily analyzed. In that each plot is also associated with a specific individual smallholder, it is also possible to determine who is connected to whom via the upstream-downstream interaction. By connecting individuals to one another as a function of the plots that they manage, the resultant network expresses the Archetype 3 network wherein the ecosystem connects the individuals using the landscape to support their livelihoods (Fig. 3b).

Fig. 3. Schematics showing plot-plot networks (a) and individual-individual networks (b).

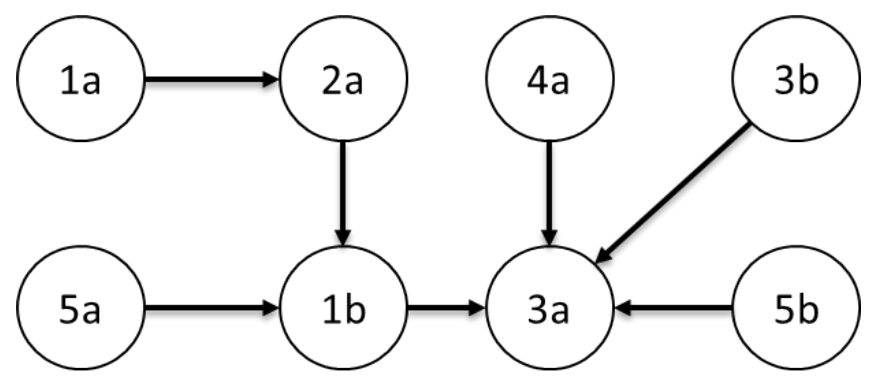

(a)

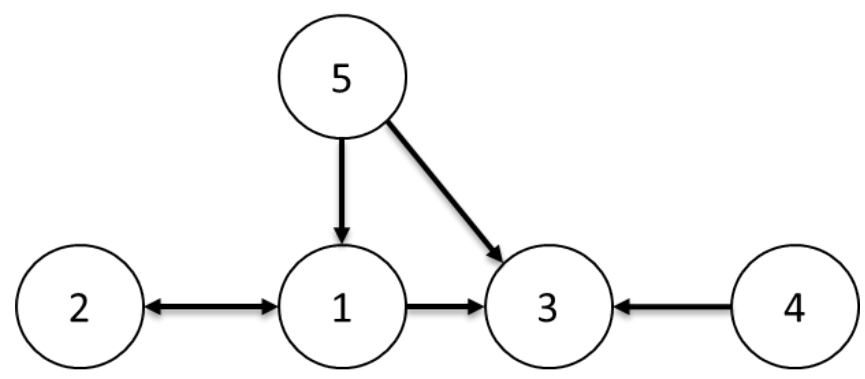

(b)

To support better understanding of the social context of the biophysical network, collected data also support construction of a network characterizing social-institutional interactions. This network, based on the survey data, characterizes the association of each individual with bonding networks (links with external actors such as extension agents) and bridging networks that link individual smallholders with actors internal to the study site such as peers and local associations or cooperatives (Newman and Dale 2005). The resultant combination of network structures (plot, individual, and bonding and bridging) allows for a range of analytic techniques that can be used to help interpret the socialecological interactions using a variety of metrics.

\section{Analyzing the networks}

Once the networks are constructed, a variety of network analytic approaches become possible. The recognition that different network characteristics have the potential to influence of the structure of networks generally (Newman 2003) is well known and that these structures have specific influences on the socialecological function of a system is also generally well accepted (Newman and Dale 2005, Bodin et al. 2006, Janssen et al. 2006).
Because the networks presented here are spatially embedded, the structures of the individual- and plot-based networks are subject to influence by both the characteristics of the space they occupy and spatial autocorrelation (Boccaletti et al. 2006).

Measures of modularity and attendant community structure in the presented networks offers information regarding subcomponents of network as a function of their reliance on particular edges to connect them to the remainder of the network (Girvan and Newman 2002). In the context of the study area subbasin, communities of plots arise as a function of the hydrological characteristics of the landscape. Also, since modularity is based on the relationship of intra- and inter-connectivity within and across groups, the modularity and community measures allow for the identification of the critical edges within the network. This decision is consistent with the recent work of Beilin et al. (2013), where modularity approaches were chosen to examine community based natural resource management across multiple scales. Beilin et al. (2013) base their selection of modularity as a key metric on the idea that, within NRM contexts, there exist subgroups that have the ability to function semiautonomously and in a manner at least partially independent of their broader contexts.

Another important network concept that has a direct relationship with spatial embedding is the notion of centrality. Centrality is a structural attribute of the network that serves to characterize the role of any given node or edge in enabling overall connectivity of the networked system (Newman 2003). In examining centrality in a social-ecological context, however, centrality may serve to indicate several potential characteristics ranging from high levels of coordination to highly centralized management (Bodin et al. 2006). In an ecologically-based system, however, high centrality may take on yet additional meaning ranging from indicators regarding the movement of organisms (Estrada and Bodin 2008) to nodes and edges that are essentially serving as the "backbone" of the ecological system (Urban et al. 2009).

\section{RESULTS}

The social-ecological systems perspective that girds this effort implies an integral coupling between ecosystems and the people that inhabit those systems. Importantly, people serve multiple roles in a social-ecological systems context. The overall function of the landscape is thus at the intersection of the ecological characteristics of the landscape itself and the collective, yet individual roles of the people residing in that landscape. In agroecosystems it is thus impossible to separate the landscape from its inhabitants or, equivalently, the social system from the ecological system.

\section{SENs for identifying "hot spots"}

An important aspect of understanding spatial resilience is related to how the centripetal and centrifugal forces affecting resilience (Cumming 2011) are distributed across the landscape. In the Fogera study site a number of important insights can be interpreted from the SENs that would be difficult to gain from other approaches.

To facilitate interpretation of the resultant SENs, the plot networks (Fig. 4) are drawn using standard network layout algorithms. Per the methods section, in both figures the nodes are colored for community membership based on modularity (Blondel et al. 2008) and scaled in size for eigenvector centrality 
(Borgatti et al. 2009). In Figure 4, the complexity of the interrelationships of the individual plots across the study site is clearly evident. The number of connections associated with each plot (each node) illustrates the complex and interconnectedness of the site and, consequently, the potential for feedbacks associated with decisions at the plot level. The communities (colors) shown in Figure 4 indicate groups of plots effectively serving as "modules" in ecological sense. As mentioned, modules can be thought of in terms of an interrelated group of plots function in a semiautonomous manner. In Figure 5a, a map of the communities illustrates that, indeed, the communities tend to be either spatially proximal or distributed along key watershed features, e.g., the riparian area.

Fig. 4. Network of individual plots. Colors represent communities defined through the modularity measure and node size represents eigenvector centrality.

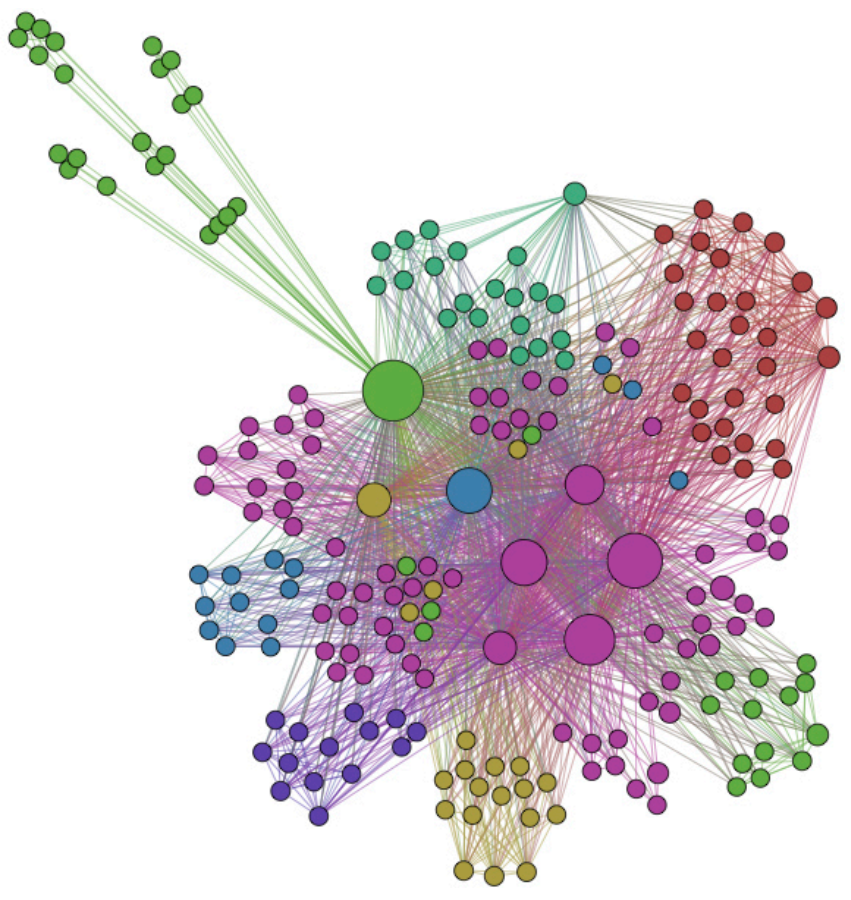

In examining Figure 5b, it is also evident that each of the communities tends to have at least one or two more central plots. These plots are similarly evidenced in Figure 4 as the larger circles and it can be easily interpreted from the network that these locations are serving as important ecological "hubs" within the study area. It is worth noting, however, that several of the more central plots (in network space) are located toward the periphery of the watershed. This finding illustrates that high centrality plots are not necessarily found in the center of the watershed and, being close to the boundary of the watershed, these plots, and the individuals using them, may be more subject to either boundary effects or the consequences of larger scale processes. Also, in contrast to social networks and a number of different technical networks, the plot-plot networks derived based on the above method lack clear redundancy of linkages associated with many resilient systems (Walker and Salt 2012). The highly central plots are connected to heavily used edges, i.e., significant hydrological reaches, and, if these edges are disrupted, e.g., through sedimentation, gully erosion, etc., then there exists a likelihood for immediate consequences on the connected nodes.

Fig. 5. Spatial distribution of plot-level community structure (a) and plot centrality (b).

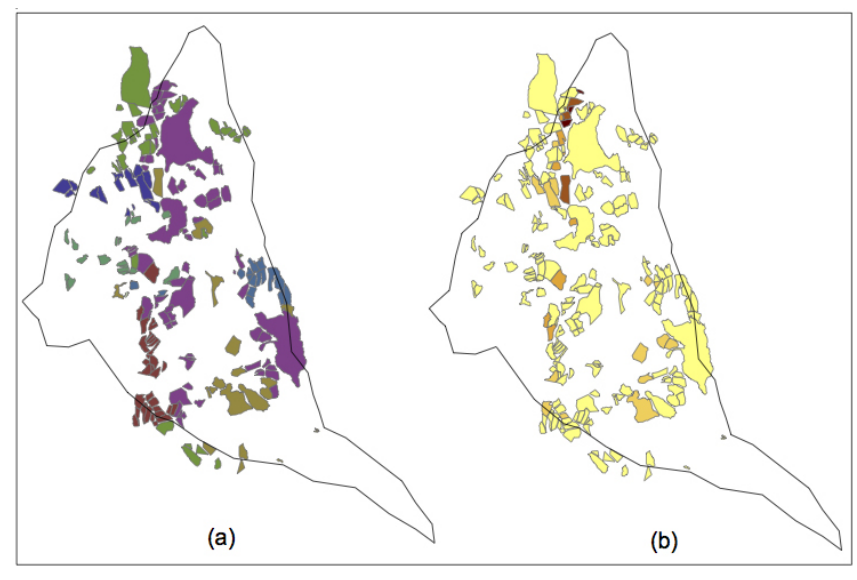

Understanding ecological hubs within the study area is only part of the picture. Whereas the network of plots shown in Figure 4 has the potential to illustrate intervention "hot spots," reconfiguring the network to examine smallholder connections based on plot locations provides additional insight. Because an individual smallholder manages each plot and smallholders may manage plots distributed throughout the watershed, smallholders have the potential to influence one another in a manner that would not necessarily be evidenced by plot level interactions. Figure 6 illustrates this network. Now, rather than a network of plots, the social-ecological network of smallholders emerges.

Fig. 6. The social-ecological network of smallholders where color indicated community membership and size indicates centrality. The pour point (PP) is the outlet of the watershed.

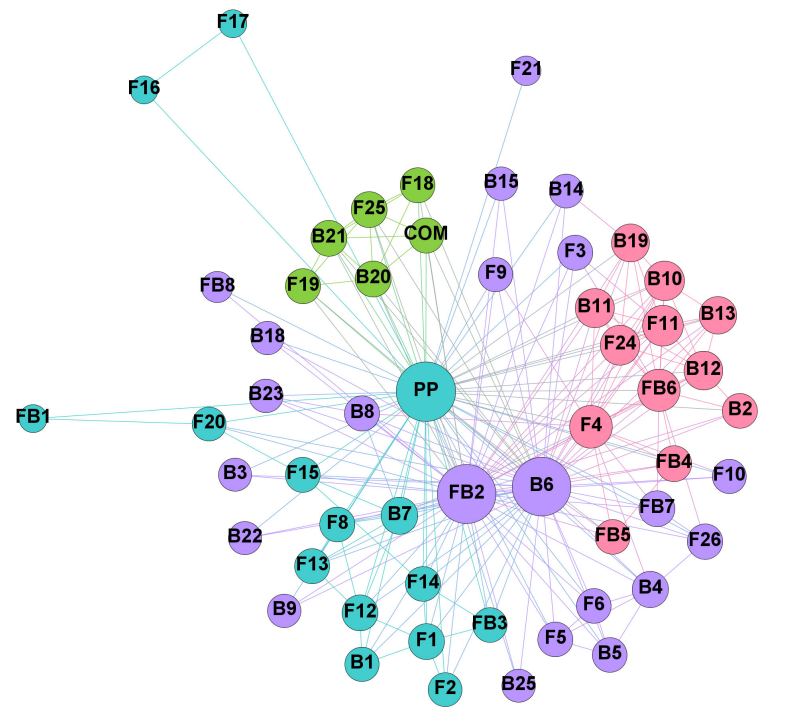


From the network of smallholders it is again possible to compute community structure and centrality. Because community is based on the structure of connectivity and many of the smallholders work multiple plots in various positions in the landscape, this is a significantly richer description of individuals' interactions with one another and human-environment interaction than characterizing upstream/downstream relationships solely in a hydrological context. The importance of location becomes immediately apparent because the two most central individuals (B6 and FB2) are very different relative to their holdings and the land that they manage. The smallholder labeled as B6 is the smallholder in this study managing the largest amount of land with a total of $\sim 5.20$ ha of which just over 4 hectares is limited to grazing. In contrast, FB2 maintains 0.70 ha of which 0.050 ha is limited to grazing.

The relevance of the SEN representation is clear, in that even managing a relatively small amount of land spread throughout a number of critical locations has the potential to expose the smallholder to significant levels of influence from upstream individuals. Likewise, much of the at-risk land managed by B6 is dedicated to grazing and, consequently, risk to subsistence and cash crop production is largely mitigated. In contrast, FB2 has much less land and greater per unit area reliance on that land for crop production.

The communities of smallholders shown in Figure 6 are also interesting in that they have the potential to identify individuals who are ecologically connected, e.g., subject to feedbacks from one another, as a function of their collective plot locations. In that these communities have a shared set of ecological connections, the ability to affect positive ecological change is potentially higher if the smallholders within each community worked toward collective management goals. One of the mechanisms through which this could occur is through interventions that use social connections to create ecological synergies among the users of the landscape. One example of this could be via the use of development teams, a form of a bridging network that serves to both link community members to one another as well as to the inputs of those with relevant expertise from outside the area. This is consistent with the idea presented by Ling and Dale (2011), that important edges could be purposefully created and maintained to promote specific development outcomes.

\section{Bridging and bonding networks}

The presence of social networks and corresponding social capital on the landscape is often invisible in natural resource management contexts (Beilin et al. 2013). Social networks among individuals clearly serve a variety of purposes from friendship to mediating the flow of information. Newman and Dale (2005) suggest that social networks that foster the greatest resilience comprised both "bonding" links, i.e., links resulting in strong internal cohesion, as well as strong "bridging" links, i.e., links supporting connections to a diverse web of resources.

To further assess the social aspects of the study area, the survey instrument addressed social capital and social networks. Smallholders were queried regarding general well-being, quality of harvest, access to technical support, community issues, membership in community groups and general interactions with others in the study area. Overall, the majority of respondents reported increases in basic economic well-being and quality of life (Fig. 7). There are no clear spatially explicit patterns in terms of responses regarding adverse change. However, individuals tending to report decreases in any area were likely to report either decreases or no change in other categories.

Fig. 7. Change in economic well-being and quality of life over the previous three years.

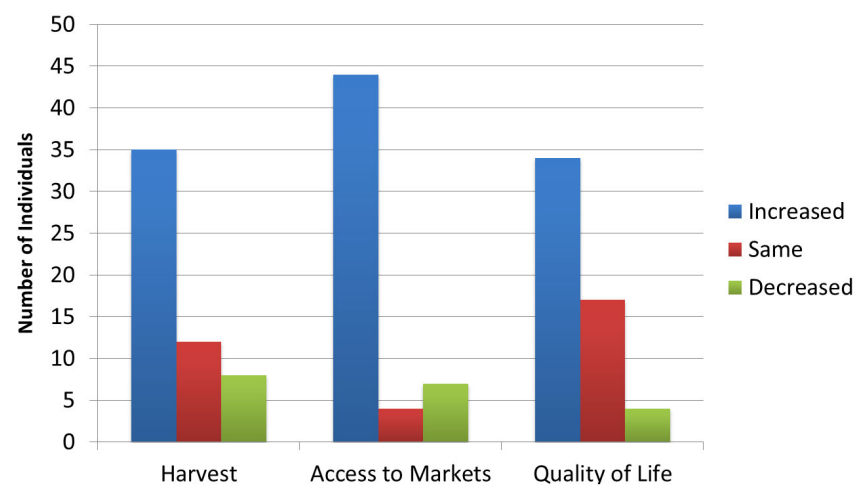

In keeping with the social-ecological context of the networks developed in the previous section, however, it is important to recall that all management decisions that modify the agroecosystem in a localized, i.e., plot-level, manner have the potential to contribute to a collective, regional modification in system function. Though smallholder management decisions are typically made in the selfinterest of the individual involved, these decisions are often made given information from resources or individuals both within and external to the study site. The relationships to influential individuals and, more specifically, the types of relationships in which each smallholder is engaged is yet another indicator of the structures of social-ecological networks within the study site.

In contrast to the networks illustrated in Figures 4 and 6, wherein nodes were all of the same type (plots or farmers), here, the network is constructed as a tripartite network. A tripartite network has three node types. Figure 8 illustrates the tripartite network, with the three node types representing "bridging" entities (top row), "bonding" entities (bottom row), as well as the smallholders (center row).

Based on the survey, bridging entities were divided into three primary categories. These included resources for external technical assistance, participation in the aforementioned development teams (e.g., organized groups of five households affiliating with a "model farmer" selected by external agricultural development agents), and cooperatives (e.g., to source seed and fertilizer at reduced rates). Overall smallholders in the study site appear to have reasonable access to bridging activities, with only four individuals reporting no bridging activities at all. External technical assistance is the most widespread bridging activity with $76 \%$ of the study participants reporting as having received technical assistance from agricultural experts, development agents, or other government entities. Although not all types of bridging activities are equally wide spread, or seen as equally 
Fig. 8. Bonding and bridging network. Relative importance of the bonding and bridging interactions are indicated by node size, and relative reliance of the smallholders on bonding and bridging indicated by node color.

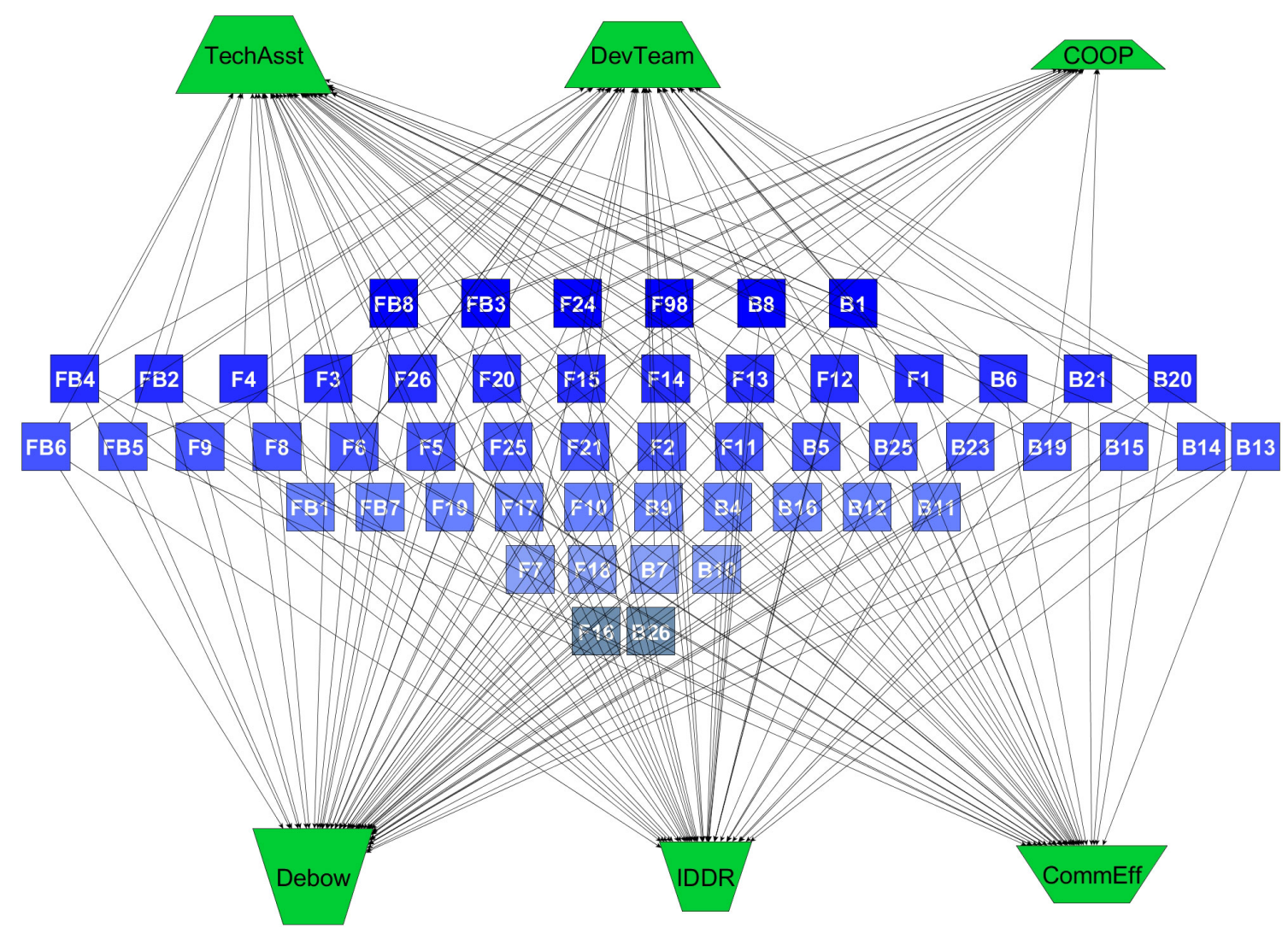

valuable, smallholders reporting improvements in harvest rates over the last three years have a statistically significant higher level of association with bridging networks (Mann-Whitney U @, 95\% confidence).

Regardless of change in any of the basic quality of life indicators (Fig. 7), there was no significant difference in participation in bonding networks among the smallholders. The primary categories of bonding entities include debow (barter in Amharic but specifically meaning exchange of day labor in this context), $i d d r$ (culturally important funeral societies), and community led efforts. The use of debow is nearly universal among study participants. Only three of the 55 (5.4\%) surveyed individuals did not report participating in debow. Likewise, the majority of smallholders $(71.0 \%)$ report participation in the socially and culturally important iddrs. Finally, roughly two-thirds of the smallholders participate in community led efforts including activities such as terracing, afforestation, education, and community security.

It is worth noting that both bonding and bridging networks have the possibility to positively affect overall resilience of the area. New ideas and approaches to agricultural management are likely to enter the study area through bridging networks. Likewise, community challenges are more likely to be communicated to external agencies. Similarly, if specific management practices are successful or community led projects are resulting in systematic improvements to the local environment, such information will travel quickly because of the strong extant bonding networks. Network approaches are again useful in terms of illustrating the interactions between individuals and the collective set of actors that may have the potential to influence spatial resilience at the local scale.

\section{DISCUSSION}

One motivation of this work is that in many instances, failure of large efforts can be traced back to lack of understanding of localscale contexts (Hoben 1995). At the same time, local activities have the potential to have significant regional influence and it is at these regional levels that many management decisions are made and corresponding policy strategies developed (Arsano and Tamrat 2005). The dependence on a common resource, yet the acute differences in power associated with actors operating at different scales is a common theme in hydrology-based socialecological systems (Molle 2007). At the same time, especially in rain-fed systems, the types of interventions required may not necessarily be prudent investments at the farm scale or for the individual farmer (Nyssen et al. 2004). The SEN-based approach for characterizing hydrology-based social-ecological systems illustrates how understanding of the local situation can be useful for both identifying hot spot priorities within a watershed and, 
especially, key or strongly linked individuals and groups for targeting meso-scale interventions. If members of these groups are strongly tied to both bonding and bridging networks and have relevant biophysical contexts, the likelihood of success for an appropriate rainwater management practice will increase.

As a community, the study area exhibits relatively high levels of success with its agriculture and community-led initiatives and the presence of what appears to be relatively high levels of social capital. Understanding resilience of the area, however, is predicated on understanding its broader scale embedding in terms of both ecological and social contexts (Deconchat et al. 2007, Ostrom 2009). The bridging networks clearly illustrate one example of larger social embedding. Necessarily, as a sub-basin within a larger watershed, the ecological embedding is clear. The bridging networks and biophysical hierarchy are only two examples of the wide range of embeddings that have the potential to affect perspectives, and thus coordination, of stakeholders in regard to the implementation of rainwater management practices.

A number of the primary challenges raised by the community members in Fogera are reflective of the broader spatial embeddings of the study area and though not directly related to rainwater management add to the understanding of what is required to create successful interventions in the area. The coops discussed in the bridging section, for example, have attempted to enhance access to fertilizer. This was consistently identified as a high priority among the smallholders yet most also indicated efforts in this area were not successful. Regardless of the reason for the lack of reported success in this area, the inability to procure fertilizer is indicative of cross-scale challenges associated with the social, economic, and political settings (Ostrom 2009) of the Fogera site. A second challenge highlighted as a critical concern by community members was deforestation by individuals from outside of the community. This deforestation is an example of Archetype 2, or ecosystem networks that are disrupted by anthropogenic change. This is a particularly challenging issue because the actions of community outsiders are not only disrupting ecosystem services within the community, but fall outside of the bridging and bonding networks illustrated in Figure 8. A final example of cross-scale linkages has to do with accessibility to regional markets. Though a portion of cropping activity is subsistence-oriented, it is also necessary to grow cash crops. The market for cash crops is tied to regional and national levels. Good connectivity to markets and strong markets are thus essential for the local success of the region.

\section{CONCLUSION}

In principle, the idea of using SENs at the local level is very attractive because of the fidelity of the representation and the level of information gain (Nyerges et al. 2013). That said, the method employed here was very labor intensive and required a great deal of time in the field. More significant, however, were sizeable contributions of time by community members. It is worth noting that the plot-plot network depicted in Figure 4 could be done through more automated methods, e.g., via remote sensing, but this would omit the direct linkages with the corresponding social information. An area for future research would be to understand how a preliminary plot-plot network might be used to devise a sampling scheme to develop a representative social- ecological network much more quickly and at a much larger scale. Addressing the temporal aspect of each of the three SEN archetypes would also be useful. For example, while the model used here is essentially static in terms of which plots are connected to which other plots, the strength of those connections may vary as a function of time, e.g., rainfall amounts.

Again, the study presented here was intentionally designed to employ social-ecological network methods as detailed by Janssen et al. (2006). In contrast to much of the related research, this study was designed around networks built at a very local and individualspecific level. If anything, this research bolsters the idea that management of a complex system such as a rain fed agroecosystem is not a hard, objective problem but, rather, is emergent and dependent on the situation, e.g., biophysical, of the individual stakeholders as well as their social contexts and related experiences (Cundill et al. 2011). The Archetype 3 networks that were constructed offer new insights into the spatial resilience of the Fogera area and some new ideas in terms of how landscapelevel interventions such as rainwater management practices might be targeted given the biophysical and social situations of the stakeholders involved.

\section{Responses to this article can be read online at: http://www.ecologyandsociety.org/issues/responses. $\mathrm{php} / 7950$}

\section{Acknowledgments:}

This research was partially funded by grant from the International Water Management Institute. The authors would like to thank the Fogera community in which this research was conducted. In addition, the authors wish to acknowledge the tireless efforts of the field crew including Jason Z. Edwards, Ryan Anderson, Fikremariam Teshome, and Belew Shisheber. Their dedication, expertise, and local knowledge were elemental to the success of this effort.

\section{LITERATURE CITED}

Abel, N., D. H. M. Cumming, and J. M. Anderies. 2006. Collapse and reorganization in social-ecological systems: questions, some ideas, and policy implications. Ecology and Society 11(1):17. [online] URL: http://www.ecologyandsociety.org/vol11/iss1/ art17l

Arsano, Y., and I. Tamrat. 2005. Ethiopia and the eastern Nile Basin. Aquatic Science 67(1):15-27. http://dx.doi.org/10.1007/ s00027-004-0766-X

Beilin, R., N. T. Reichelt, B. J. King, A. Long, and S. Cam. 2013. Transition landscapes and social networks: examining on-ground community resilience and its implications for policy settings in multiscalar systems. Ecology and Society 18(2):30. http://dx.doi. org/10.5751/es-05360-180230

Binder, C. R., J. Hinkel, P. W. G. Bots, and C. Pahl-Wostl. 2013. Comparison of frameworks for analyzing social-ecological systems. Ecology and Society 18(4):26. http://dx.doi.org/10.5751/ es-05551-180426 
Blondel, V. D., J. L. Guillaume, R. Lambiotte, and E. Lefebvre. 2008. Fast unfolding of communities in large networks. Journal of Statistical Mechanics: Theory and Experiment 2008(10). http:// dx.doi.org/10.1088/1742-5468/2008/10/p10008

Boccaletti, S., V. Latora, Y. Moreno, M. Chavez, and D.-U. Hwang. 2006. Complex networks: structure and dynamics. Physics Reports 424(4-5):175-308. http://dx.doi.org/10.1016/j. physrep.2005.10.009

Bodin, Ö., and B. I. Crona. 2009. The role of social networks in natural resource governance: What relational patterns make a difference? Global Environmental Change 19(3):366-374. http:// dx.doi.org/10.1016/j.gloenvcha.2009.05.002

Bodin, Ö., B. Crona, and H. Ernstson. 2006. Social networks in natural resource management: What is there to learn from a structural perspective? Ecology and Society 11(2):r2. [online] URL: http://www.ecologyandsociety.org/vol11/iss2/resp2/

Borgatti, S. P., A. Mehra, D. J. Brass, and G. Labianca. 2009. Network analysis in the social sciences. Science 323 (5916):892-895. http://dx.doi.org/10.1126/science.1165821

Cumming, G. S. 2011. Spatial resilience in social-ecological systems. Springer, Dordrecht, The Netherlands. http://dx.doi. org/10.1007/978-94-007-0307-0

Cumming, G. S., and J. Collier. 2005. Change and identity in complex systems. Ecology and Society 10(1):29. [online] URL: http://www.ecologyandsociety.org/vol10/iss1/art29/

Cundill, G., G. S. Cumming, D. Biggs, and C. Fabricius. 2011. Soft systems thinking and social learning for adaptive management. Conservation Biology 26(1):13-20. http://dx.doi. org/10.1111/j.1523-1739.2011.01755.x

Deconchat, M., A. Gibon, A. Cabanettes, G. du Bus de Warnaffe, M. Hewison, E. Garine, A. Gavaland, J.-P. Lacombe, S. Ladet, C. Monteil, A. Ouin, J.-P. Sarthou, A. Sourdril, and G. Balent. 2007. How to set up a research framework to analyze socialecological interactive processes in a rural landscape. Ecology and Society 12(1):15. [online] URL: http://www.ecologyandsociety. org/vol12/iss1/art15/

Ehrhardt, G., M. Marsili, and F. Vega-Redondo. 2007. Emergence and resilience of social networks: a general theoretical framework. Annales d'Economie et de Statistique 86:1-13.

Elmore, A. J., J. F. Mustard, S. P. Hamburg, and S. J. Manning. 2006. Agricultural legacies in the Great Basin alter vegetation cover, composition, and response to precipitation. Ecosystems 9 (8):1231-1241. http://dx.doi.org/10.1007/s10021-005-0069-7

Estrada, E., and Ö. Bodin. 2008. Using network centrality measures to manage landscape connectivity. Ecological Applications 18(7):1810-1825. http://dx.doi.org/10.1890/07-1419.1

Folke, C., S. Carpenter, T. Elmqvist, L. Gunderson, C. S. Holling, and B. Walker. 2002. Resilience and sustainable development: building adaptive capacity in a world of transformations. AMBIO: A Journal of the Human Environment 31(5):437-440. http://dx.doi.org/10.1579/0044-7447-31.5.437

Girvan, M., and M. E. J. Newman. 2002. Community structure in social and biological networks. Proceedings of the National
Academy of Sciences 99(12):7821-7826. http://dx.doi.org/10.1073/ pnas. 122653799

Grootaert, C., and T. Van Bastelar, editor. 2002. Understanding and measuring social capital: a multidisciplinary tool for practitioners. World Bank Publications, Washington, D.C., USA. http://dx.doi.org/10.1596/0-8213-5068-4

Hoben, A. 1995. Paradigms and politics: the cultural construction of environmental policy in Ethiopia. World Development 23 (6):1007-1021. http://dx.doi.org/10.1016/0305-750x(95)00019-9

Janssen, M. A., Ö. Bodin, J. M. Anderies, T. Elmqvist, H Ernstson, R. R. J. McAllister, P. Olsson, and P. Ryan. 2006. Toward a network perspective on the resilience of socialecological systems. Ecology and Society 11(1):15. [online] URL: http://www.ecologyandsociety.org/vol11/iss1/art15/

Levin, S. A., and W. C. Clark, editors. 2010. Toward a science of sustainability. Center for International Development Working Papers 196, John F. Kennedy School of Government, Harvard University, Cambridge, Massachusetts, USA. [online] URL: https://dash.harvard.edu/handle/1/9774654

Linard, C., M. Gilbert, R. W. Snow, A. M. Noor, and A. J. Tatem. 2012. Population distribution, settlement patterns and accessibility across Africa in 2010. PLoS ONE 7(2):e31743. http:// dx.doi.org/10.1371/journal.pone.0031743

Ling, C., and A. Dale. 2011. Nature, place and the creative class: three Canadian case studies. Landscape and Urban Planning 99 (3-4):239-247. http://dx.doi.org/10.1016/j.landurbplan.2010.11.006

Merrey, D. J., and T. Gebreselassi. 2011. Promoting improved rainwater and land management in the Blue Nile (Abay) basin of Ethiopia. Nile Basin Development Challenge: Technical Report - 1. International Livestock Research Institute, Nairobi, Kenya.

Molle, F. 2007. Scales and power in river basin management: the Chao Phraya River in Thailand. Geographical Journal 173 (4):358-373. http://dx.doi.org/10.1111/j.1475-4959.2007.00255.x

Newman, L. L., and A. Dale. 2005. Network structure, diversity, and proactive resilience building: a response to Tompkins and Adger. Ecology and Society 10(1):r2. [online] URL: http://www. ecologyandsociety.org/vol10/iss 1/resp2/

Newman, M. E. J. 2003. The structure and function of complex networks. Society for Industrial and Applied Mathematics Review 45(2):167-256. http://dx.doi.org/10.1137/s003614450342480

Nyerges, T., M. Roderick, S. Prager, D. Bennett, and N. Lam. 2013. Foundations of sustainability information representation theory: spatial-temporal dynamics of sustainable systems. International Journal of Geographical Information Science 28 (5):1165-1185. http://dx.doi.org/10.1080/13658816.2013.853304

Nyssen, J., J. Poesen, J. Moeyersons, J. Deckers, M. Haile, and A. Lang. 2004. Human impact on the environment in the Ethiopian and Eritrean highlands - a state of the art. Earth-Science Reviews 64(3-4):273-320. http://dx.doi.org/10.1016/s0012-8252(03)00078-3

Ostrom, E. 2009. A general framework for analyzing sustainability of social-ecological systems. Science 325 (5939):419-422. http://dx.doi.org/10.1126/science.1172133 
Prell, C., K. Hubacek, and M. Reed. 2009. Stakeholder analysis and social network analysis in natural resource management. Society and Natural Resources 22(6):501-518. http://dx.doi. org/10.1080/08941920802199202

Quinn, P., K. Beven, P. Chevallier, and O. Planchon. 1991. The prediction of hillslope flow paths for distributed hydrological modelling using digital terrain models. Hydrological Processes 5 (1):59-79. http://dx.doi.org/10.1002/hyp.3360050106

Rathwell, K. J., and G. D. Peterson. 2012. Connecting social networks with ecosystem services for watershed governance: a social-ecological network perspective highlights the critical role of bridging organizations. Ecology and Society 17(2):24. http:// dx.doi.org/10.5751/es-04810-170224

Reed, M. S., A. Graves, N. Dandy, H. Posthumus, K. Hubacek, J. Morris, C. Prell, C. H. Quinn, and L. C. Stringer. 2009. Who's in and why? A typology of stakeholder analysis methods for natural resource management. Journal of Environmental Management 90(5):1933-1949. http://dx.doi.org/10.1016/j. jenvman.2009.01.001

Ripl, W. 2003. Water: the bloodstream of the biosphere. Philosophical Transactions of the Royal Society of London. Series B: Biological Sciences 358(1440):1921-1934. http://dx.doi. org/10.1098/rstb.2003.1378

Ryan, J. G., C. A. McAlpine, and J. A. Ludwig. 2010. Integrated vegetation designs for enhancing water retention and recycling in agroecosystems. Landscape Ecology 25(8):1277-1288. http://dx. doi.org/10.1007/s10980-010-9509-7

Urban, D. L., E. S. Minor, E. A. Treml, and R. S. Schick. 2009. Graph models of habitat mosaics. Ecology Letters 12(3):260-273. http://dx.doi.org/10.1111/j.1461-0248.2008.01271.x

Urban, D. L., and T. Keitt. 2001. Landscape connectivity: a graph-theoretic perspective. Ecology 82(5):1205-1218. http://dx. doi.org/10.1890/0012-9658(2001)082[1205:lcagtp]2.0.co:2

Walker, B., and D. Salt. 2012. Resilience thinking: sustaining ecosystems and people in a changing world. Island Press, Washington, D.C., USA.

Wong, L. H., P. Pattison, and G. Robins. 2006. A spatial model for social networks. Physica A: Statistical Mechanics and its Applications 360(1):99-120. http://dx.doi.org/10.1016/j.physa.2005.04.029 
Appendix 1. Survey questions used in the field data collection campaigns. This survey was translated to Amharic and contextualized to cultural norms in the region (e.g., names of specific community organizations, specific types of social interactions, etc.). An IRB approved informed consent was read in Amharic prior to each engagement.

\section{Household Questions}

0 ) What is the gender of the participant?

$\begin{array}{ll}\text { Male } & {[\text { ] }} \\ \text { Female } & {[\text { ] }}\end{array}$

0.1) Are you head of household?

$\begin{array}{ll}\text { Yes } & {[]} \\ \text { No } & {[}\end{array}$

0.2) If no, what is the gender of the head of household?

Male [ ]

Female $\quad[$ ]

1) How many people live in your household?

2) How many adults?

3) What are the three principal agricultural or livestock activities in this community?

4) What are the two most important problems facing members of this community for getting their products to market and making a profit?

5) In the last three years, has the community led efforts to address an agricultural issue, market issue or other community problem?

$\begin{array}{ll}\text { Yes } & {[} \\ \text { No } & {[}\end{array}$

5a) What issue or issues?

5b) Was/were the initiative(s) successful?

$\begin{array}{llll} & \text { YES } & \text { NO } & \text { ON GOING } \\ \text { Initiative (a) } & {[\text { ] }} & {[\text { ] }} & {[\text { ] }} \\ \text { Initiative (b) } & {[\text { ] }} & {[\text { ] }} & {[\text { ] }}\end{array}$

5c) What are the two main problems this community needs to solve? 
6) Do agricultural workers/producers in this community receive technical assistance?

$\begin{array}{ll}\text { Yes } & {[} \\ \text { No } & {[}\end{array}$

5a) If yes, who is the main provider?

7) Does this community have any type of agricultural cooperative?

$\begin{array}{ll}\text { Yes } & {[} \\ \text { No } & {[}\end{array}$

7a) If yes, what is its purpose?

8) In the last three years, the harvests/ yields have:

$\begin{array}{ll}\text { Increased } & {[\text { ] }} \\ \text { Decreased } & {[\text { ] }} \\ \text { Remained the same } & {[\text { ] }}\end{array}$

9) In the last three years, the sales of agricultural/livestock products in this community have:

$\begin{array}{ll}\text { Increased } & {[\text { ] }} \\ \text { Decreased } & {[\text { ] }} \\ \text { Remained the same } & {[\text { ] }}\end{array}$

10) In the last three years, the overall quality of life in this community has:

$\begin{array}{ll}\text { Increased } & {[\text { ] }} \\ \text { Decreased } & {[\text { ] }} \\ \text { Remained the same } & {[\text { ] }}\end{array}$

11) Do members of the household participate in an iddr?

Iddr $\mathrm{Y} / \mathrm{N}$

if yes, how many,

if no, why?

12) Does your household hire labor for the household or farm?

12a) What kind of labor?

12b) Where do the laborers come from?

13) Does your household participate in debow (local form of barter)? If so, for what?

14) Does your household participate in a development team (use regional term)?

14a) If yes, is a member of your household a leader for a development team? 
15) How many livestock do you own?

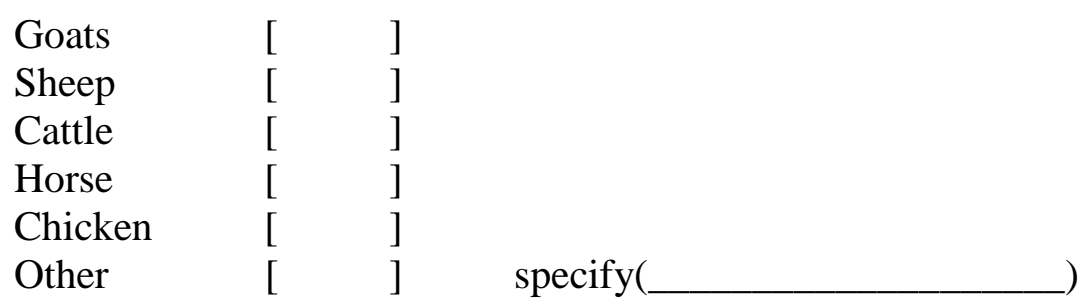

16) What forms of income, other than through agriculture or livestock, do you use to support your household?

17) Who participates most in addressing agricultural issues, market issues, and related problems in the community?

$\begin{array}{ll}\text { Men } & \text { [ ] } \\ \text { Women } & {[\text { ] }} \\ \text { Men and women equally } & {[\text { ] }} \\ \text { Neither participates } & {[\text { ] }}\end{array}$

18) How does this community manage grazing in agriculture fields?
As a community
Individually
Grazing is not managed
[ ]
[ ]
Other
[ ]
[ ] Specify

19) If grazing occurs, from where do the livestock come? (if multiple locations, specify) 
Appendix 2. Social network and mapping protocol. As with the survey, this process was translated to Amharic and contextualized for the region.

\section{For each farmer:}

What plots do you own or rent? (on map or in field, record specific plots rented or owned)

Which other farmers in the local area do you maintain close relationships with? (either show on map or walk the field)

Which plots in the local area do those farmers work?

For each of those farmers, what is you main relationship? (self identified relation type)

With each farmer, do you also share membership in community organizations such as iddr, mahiber, iquub, church, water organization, or other? What?

For each of those famers that you identified, do you also maintain any of the following relationships:

I provide him or her with advice on agricultural issues.

They provide me with advice on agricultural issues.

[ ]

They provide labor on my plot.

[ ]

I provide labor to their plot.

[ ]

I lease land to him or her.

[ ]

They lease land to me.

[ ]

I help them handle problems or when they are in need.

They help me handle problems or when I am in need.

[ ]

We share resources.

[ ]

We work cooperatively/sharecropping.

[ ]

We are friends.

[ ]

We are members of the same community group.

We pair oxen.

Other (please identify

For each farmer (1-n), do you share information about agricultural practices? What is the primary issue that you discuss?

Have you implemented soil water conservation practices? (give examples?)

$$
\text { Yes [ ] No [ ] }
$$

If yes, what and for how long? 